\title{
EMPREENDEDORISMO CRIATIVO: MAPEAMENTO SISTEMÁTICO DA LITERATURA NA PLATAFORMA SCOPUS
}

\author{
Bibiana Silveira-Nunes \\ Mestranda em Indústria Criativa - Universidade Feevale \\ http://orcid.org/0000-0002-9994-4241 \\ bibianasilveira@gmail.com
}

\author{
Cristiano Max Pereira Pinheiro \\ Doutor em Comunicação Social \\ Professor no Mestrado em Indústria Criativa - Universidade Feevale \\ http://orcid.org/0000-0002-2038-8191 \\ maxrs@feevale.br
}

\author{
Sandra Portella Montardo \\ Doutora em Comunicação Social \\ Professora no Mestrado em Indústria Criativa, nos Programas de Pós-Graduação em \\ Processos e Manifestações Culturais e Inclusão Social e Acessibilidade - Universidade Feevale \\ http://orcid.org/0000-0001-8336-9329 \\ sandramontardo@feevale.br
}

\section{Resumo}

\begin{abstract}
Objetivamos realizar mapeamento sistemático da produção científica no domínio do tema empreendedorismo criativo no que tange à Indústria Criativa, a fim de estabelecer a melhor nomenclatura para uso em estudos relacionados ao tema. É também objetivo retratar o movimento de publicações na área e validar a necessidade de pesquisa aprofundada sobre o tema. Realizamos levantamento quantitativo de natureza básica, que busca exploração bibliográfica do tema seguindo procedimentos apontados pela bibliometria. Focamos em documentos disponíveis na base de dados SCOPUS, produzidos até 2015. A análise dos resultados aponta uma maior produção relacionada a partir do ano 2009, sendo o ano de maior produção 2015, a fonte mais citada o Journal of Small Business and Enterprise Development. Nenhum autor se destaca com maior produção. Quanto a Instituições de origem, destacamse Vrije Universiteit Amsterdam da Holanda e Queensland University of Technology - QUT da Austrália com 4 documentos cada. O Reino Unido lidera em produção com 35 documentos indexados, sendo que artigos científicos respondem por $66,5 \%$ destes. No que diz respeito a áreas de estudo, mostram proeminência a área de Negócios, Administração e Contabilidade com um total de 51,2\% dos resultados, e Ciências Sociais com um total de 45,1\% das publicações indexadas. Importante lembrar que um mesmo documento pode estar associado a diversos autores, instituições, países e áreas de conhecimento. Os resultados mostram que a melhor nomenclatura para referência ao tema é Empreendedorismo na Indústria Criativa, por estarem disponíveis mais resultados associados a este segmento do campo científico Indústria Criativa.
\end{abstract}

Palavras-chave: Empreendedorismo criativo. Bibliometria. SCOPUS.

\section{CONSIDERAÇÕES INICIAIS}

O Empreendedorismo Criativo vem crescendo em importância no mercado brasileiro (SEBRAE, 2016). Prova disso são os inúmeros cursos livres, comunidades virtuais e programas institucionais e governamentais ligados ao tema. No âmbito acadêmico, especialmente no campo de estudos da Indústria Criativa, o principal problema encontrado até o momento no estudo do tema revolve acerca da sua nomenclatura. Mais especificamente, na variedade de termos encontrados na literatura científica referindo o tema e seu uso, e a 
dificuldade de encontrar tal material. Os termos variam de empreendedorismo criativo a empreendedorismo em setores criativos, passando por empreendedorismo na indústria criativa e sua variável no plural.

Objetivamos, por meio deste trabalho, apresentar mapeamento sistemático da produção científica no domínio do tema empreendedorismo criativo, especificamente no que tange à Indústria Criativa, buscando esclarecer a questão da nomenclatura no que tange o tema. Objetivamos também retratar o movimento de publicações na área e validar a necessidade de pesquisa aprofundada sobre o tema. Esperamos, a partir desse levantamento inicial, jogar luz na questão e conseguir definir qual o termo mais adequado para a pesquisa em curso que gerou o presente artigo, a saber estudo do uso de sites de redes sociais pelo empreendedorismo criativo no Brasil.

Para tanto, realizamos levantamento quantitativo de natureza básica, que busca exploração bibliográfica do tema seguindo os procedimentos apontados pela bibliometria. Focamos o estudo em documentos disponíveis na plataforma SCOPUS, por ser esta referência na indexação de conteúdo científico. Como termos-filtro utilizamos as variantes até o momento encontradas no estudo do tema, a saber empreendedor/ empreendedorismo criativo, empreendedor/ empreendedorismo nos setores criativos e empreendedor/ empreendedorismo na Indústria Criativa.

Estruturamos o presente trabalho da seguinte maneira: após as Considerações Iniciais, fazemos uma breve apresentação dos Conceitos chave do estudo Empreendedorismo e Indústria Criativa na seção 2; na seção 3 apresentamos os Procedimentos Metodológicos seguidos para realizar o estudo; na seção 4 discutimos os Resultados alcançados; encerramos o artigo com as Considerações Finais e Referências.

\section{CONCEITOS}

Apresentamos aqui conceitos básicos para compreensão dos grandes temas do estudo que tornam necessária a atual pesquisa. Por não serem estes os pontos centrais do presente, e sim um levantamento sistemático da bibliografia disponível na Plataforma SCOPUS acerca dos temas, nos limitamos a uma breve apresentação dos mesmos. Iniciaremos por breve introdução ao campo de estudos empreendedorismo criativo, seguido por breve consideração acerca da Indústria Criativa.

\subsection{EMPREENDEDORISMO CRIATIVO}

No contexto do presente estudo, partimos da definição de empreendedorismo como a prática da criação de empresas que têm como diferencial a inovação. Tomamos como referências para tal definição o trabalho de Dornelas et al. (2010) e Birley \& Muzyca (2010), definições de economia criativa por Howkins (2012) e apontamentos do British Council (2016) sobre o empreendedorismo criativo.

Dornelas et al. (2010) veem no empreendedorismo a ação a partir de uma oportunidade pontual, que objetiva criação e captura de valor. De acordo com os autores, os resultados afetam todos envolvidos no processo, além dos proprietários da organização. Colocam a essência do processo na "criação e/ou reconhecimento de oportunidades, seguidos da disposição e da iniciativa para aproveitar essas" (idem, p.7575). Apresentam três características básicas que definem o espírito empreendedor: a necessidade de realização, a disposição para assumir riscos, e a autoconfiança.

Birley e Muzyca (2010) apontam como característica comum a empreendedores a "capacidade empreendedora", sendo esses "[...] indivíduos que organizam, operam e assumem os riscos associados com um empreendimento que criaram, visando à concretização de uma oportunidade que eles e outros identificaram" (BIRLEY \& MUZYCA, 2001, p.XIII). De acordo com os autores, o processo depende da identificação de oportunidades e agregação de valor, nos setores público e privado, em pequenas empreitadas e em grandes organizações. Ainda apontam a "capacidade empreendedora" como sendo potencialmente ilimitada em termos de crescimento, diferente da "pequena empresa". Também, colocam sua diferença em seu foco na geração de "um retorno razoável para os esforços das poucas pessoas que trabalham no empreendimento" (ibidem).

Dornelas et al. (2010) contrapõem essa visão de "capacidade empreendedora" oposta a "pequena empresa" citando Smith, que aponta a existência de diferentes estilos de 
empreender. Para tanto, Smith sugere um continuum que tem em seus extremos dois padrões básicos: empreendedores artesãos e empreendedores oportunistas. Os empreendedores artesãos tendem a basear sua prática em conhecimentos prévios e experiência técnica, colocando em segundo plano o planejamento em longo prazo; já empreendedores oportunistas têm formação técnica ou experiência prática em negócios e educações suplementares, e tendem a agir sobre oportunidades identificadas, aplicando ferramentas e estratégias que visam o crescimento do empreendimento.

Quanto ao empreendedor criativo, ligado à Economia Criativa que tem como matéria prima a criatividade e o capital intelectual (HOWKINS, 2001), acreditamos que ele pode se encaixar em qualquer ponto desse continuum. Para o British Council (2016), referência em assuntos relacionados à Economia Criativa, o empreendedor criativo pode ser definido como:

1) indivíduo trabalhando no setor criativo que tenha demonstrado sucesso nos negócios nos termos clássicos de crescimento de negócios, e/ou em termos de sua reputação entre seus pares;

2) individuo trabalhando no setor criativo que tenha desenvolvido um empreendimento social ou sem fins lucrativos, bem sucedido em termos de impacto e alcance;

3) indivíduo trabalhando no setor criativo que tenha mostrado liderança na indústria ao promover seu desenvolvimento em seu país;

4) indivíduo trabalhando no setor criativo que tenha desenvolvido iniciativas que desenvolvem e crescem o mercado para este setor em seu país.

5) Portanto, tomamos como empreendedorismo criativo a prática da criação de empreendimentos de base inovadora que tem como matéria prima a criatividade e o capital intelectual. Estas objetivam criação e captura de valor a partir de oportunidades identificadas, que têm à frente o empreendedor responsável pela organização e operação e por assumir os riscos associados, e cujos índices de sucesso podem estar aliados aos termos da economia clássica ou criativa. Esse empreendimento pode partir de conhecimentos prévios do empreendedor, no caso artesão, ou da identificação de oportunidade, o empreendedor oportunista, ou de qualquer posição no continuum entre os dois pontos.

Para o presente estudo, então, definimos empreendedorismo criativo como a criação de empresas baseadas na inovação, com $o$ objetivo de criação e captura de valor, concretizando uma oportunidade identificada, cujo sucesso pode ser mensurado em termos de economia tradicional ou criativa. São empreendedores indivíduos responsáveis por organizar, operar e assumir os riscos associados a essa concretização. E, por seu estilo, empreendedores criativos podem ser definidos como artesãos ou oportunistas, ou qualquer posição no continuum entre esses dois extremos.

\subsection{INDÚSTRIA CRIATIVA}

No que tange o presente estudo, e por não ser essa definição o foco principal, conceituamos Indústria Criativa como os setores da economia identificados como criativos e que visam a inovação. São estes setores cujo produto imaterial carrega alto valor simbólico (DEHEINZELIN, 2011), que têm como características da sua forma de produção variedade infinita e perenidade do produto, o consumo de demanda instável, e o uso intensivo de novas tecnologias de informação e comunicação (TICs). O conceito, herdeiro da Indústria Cultural e desenvolvido pelo governo Britânico nos anos 1990, coloca Comunicação no centro de um setor em crescimento, definido para incluir desde manifestações culturais a softwares e entretenimentos digitais (CUNNINGHAM, 2010). Como campo de estudos científicos a Indústria Criativa é relativamente nova e de natureza interdisciplinar, sendo objeto de estudo de diversos campos científicos associados a seus setores, entre eles Comunicação e Administração. 
Buscando delimitar o conceito de Indústria Criativa, Bendassoli et al. (2009) apontam seus quatro componentes principais: criatividade como elemento central; cultura como objeto cultural, de valor atribuído pelo consumidor durante $\mathrm{o}$ ato de consumo; transformação desses significados em propriedade intelectual, transformada em valor econômico; ponto de convergência entre artes, negócios e tecnologia. Agrupam também as características da Indústria Criativa em três blocos, o da forma de produção, o das características do produto e das características do consumo. Os setores da economia classificados como criativos são: publicidade, arquitetura, mercado de artes e antiguidades, artesanato, design, design de moda, cinema, software, softwares interativos para lazer, música, artes performáticas, indústria editorial, rádio, tv, museus, galerias, e atividades relacionadas às tradições culturais (BENDASSOLLI et al., 2009; DCMS, 2008; HANSON, 2012).

Bendassoli et al (2009) também apontam a importância das TICs, tanto na criação de valor de mercado do produto, quanto na sua produção, promoção e distribuição, que acontecem mediadas por sites de redes sociais e aparatos tecnológicos. "Tal condição permite a descentralização das atividades [...] sistema no qual pequenas empresas ou pequenas comunidades de produtores utilizam tecnologias de informação e de comunicação para disseminar suas criações" (BENDASSOLI et al, 2009, p. 13). O mesmo vale para grandes empresas que se valem de TICs para ações de marketing, vendas online e relacionamento com cliente.

O crescimento do campo cientifico Indústria Criativa é apontado por Pinheiro; Barth (2014) através de pesquisa que deu origem à atual. Nela, os autores apontam, de maneira tangível, o crescimento da produção científica sobre o assunto, principalmente a partir de 2009. Sugerem a ampliação do estudo através da vinculação do termo Indústria Criativa a outros relacionados, o que induziu a presente pesquisa.

\section{PROCEDIMENTOS METODOLÓGICOS}

Como referência metodológica utilizamos a bibliometria, "conjunto de leis e princípios empíricos que contribuem [...] [para o] esclarecimento dos processos científicos e tecnológicos, por meio da contagem de documentos" (GUEDES; BORSCHIVER, 2005). É uma ferramenta estatística usada para o mapeamento e geração de indicadores de gestão e tratamento de informação e conhecimento, que permitem a avaliação e gestão de ciência e tecnologia. De acordo com as autoras,

[...] é também um instrumento quantitativo, que permite minimizar a subjetividade inerente à indexação e recuperação das informações, produzindo conhecimento, em determinada área de assunto. Em última análise ela contribui para tomadas de decisão na gestão da informação e do conhecimento, uma vez que auxilia na organização e sistematização de informações científicas e tecnológicas (idem, p.15).

Buscamos artigos vinculados ao tema "Empreendedorismo criativo" na base de dados eletrônica SCOPUS, "que, por sua abrangência e importância, permite inferências consistentes sobre o assunto" (PINHEIRO; BARTH, 2014, p.53). Optamos por suprimir os resultados referentes ao ano 2016 por estarmos, no momento de realização da análise, em julho do mesmo.

Como o objetivo da investigação é determinar a melhor terminologia em uso para indicar o empreendedorismo na Indústria Criativa, utilizamos uma gama de termos-filtro encontramos até o momento em buscas nãoestruturadas sobre o assunto. Os termos-filtro foram procurados em inglês, por se tratar de uma base de dados internacional. Em todas as buscas, foram assinaladas as opções Article Title, Abstract, Keywords (termo constando no título, resumo ou nas palavras-chave do artigo); no campo Published, All years to Present (todas publicações ocorridas até o presente); All no campo Document Type (todos tipos de documentos); e, em Subject Areas, deixamos todas as opções assinaladas (contemplando todas as áreas de estudo disponíveis pela plataforma). Também, os termos-filtro foram buscados entre aspas, garantindo assim resultados dentro do contexto semântico desejado. A Figura 1 ilustra o processo de busca com dois termos-filtro usando a variável $A N D$, a qual busca ocorrência de ambos os termos, sem ordem de importância. 
Figura 1 - Busca de termos-filtro com variável AND na base de dados SCOPUS

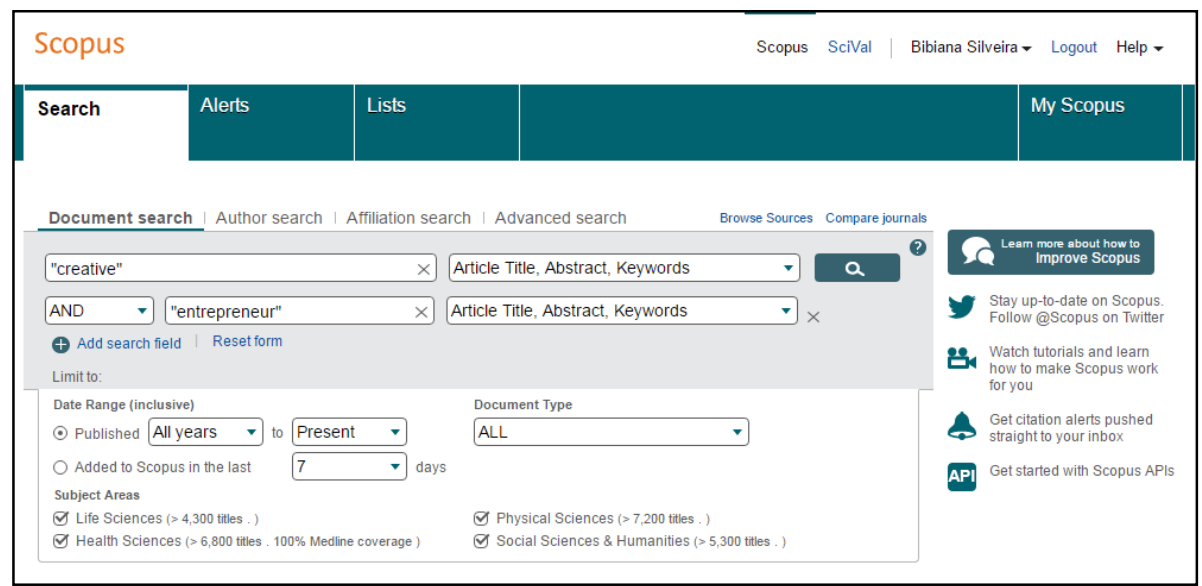

Fonte: capturado pelos pesquisadores (SCOPUS, 2016, online).

Começamos a pesquisa por quatro buscas iniciais, as quais usaram variações dos seguintes termos-filtro: pesquisa 1 "empreendedor criativo"; pesquisa 2 "empreendedor" e "indústria criativa"; pesquisa 3 - "empreendedor" e "setores criativos", e pesquisa 4 - "empreendedor" e "criativo" usando a variável AND. As buscas foram também realizadas substituindo o termo "empreendedor" - pesquisa "a" - pelo o termo "empreendedorismo" - pesquisa "b". Os resultados foram salvos, recurso disponibilizado pela plataforma.

Para evitar resultados duplicados e consolidar os dados, optamos por consolidar as duas buscas - pesquisa a e pesquisa $\mathrm{b}$ - através da ferramenta "Combine", também disponibilizada pela plataforma. Esta combina buscas salvas e consolida os dados. Para esse segundo momento, utilizamos a variável $O R$ para excluir dos resultados possíveis documentos duplicados. Em um terceiro momento, visando validar os resultados e confirmar as hipóteses colocadas em função destes, realizamos Pesquisa 5. Esta consistiu da combinação das Pesquisas 1, 2, 3 e 4, usando a variável $O R$. Estes resultados levaram à Pesquisa 6, combinação das Pesquisas 1, 2 e 3 usando a variável $O R$. O Quadro 1 mostra os termos-filtro e o tipo de variável utilizado de acordo com cada pesquisa.

Quadro 1 - Indicador da pesquisa, termos-filtro e tipo de filtro utilizados.

\begin{tabular}{|l|l|l|}
\hline Pesquisa & Termos-filtro & Variável \\
\hline Pesquisa 1 & combinação pesquisas 1a e 1b & OR \\
\hline Pesquisa 1a & "creative entrepreneur" & AND \\
\hline Pesquisa 1b & "creative entrepreneurship" & AND \\
\hline Pesquisa 2 & combinação pesquisas 2a e 2b & OR \\
\hline Pesquisa 2a & "creative industries" e "entrepreneur" & AND \\
\hline Pesquisa 2b & "creative industries" e "entrepreneurship" & AND \\
\hline Pesquisa 3 & combinação pesquisas 3a e 3b & OR \\
\hline Pesquisa 3a & "creative sectors" e "entrepreneur" & AND \\
\hline
\end{tabular}




\begin{tabular}{|l|l|l|}
\hline Pesquisa 3b & "creative sectors" e "entrepreneurship" & AND \\
\hline Pesquisa 4 & combinação pesquisas 4a e 4b & OR \\
\hline Pesquisa 4a & "creative" e "entrepreneur" & AND \\
\hline Pesquisa 4b & "creative" e "entrepreneurship" & AND \\
\hline Pesquisa 5 & Combinação das Pesquisas 1, 2, 3 e 4 & OR \\
\hline Pesquisa 6 & Combinação das Pesquisas 1, 2 e 3 & OR \\
\hline
\end{tabular}

Fonte: elaborado pelos autores.

A seguir apresentamos os resultados do mapeamento bibliométrico realizado.

\section{RESULTADOS}

\subsection{PESQUISA 1}

A busca simples pelos termos-filtro "creative entrepreneur" e "creative entrepreneurship" separadamente mostrou resultados de 38 publicações relacionadas a "creative entrepreneur" (Pesquisa 1a) e 24 relacionadas a "creative entrepreneurship" (Pesquisa 1b), um total de 62 documentos. A consolidação da busca (Pesquisa 1) apresentou 61 resultados, portanto sobreposição de 1 documento, publicados entre 1989 e 2015.

O ano de maior publicação foi 2012. Não há fonte,autor ou instituição preponderante. Em relação ao país de origem da publicação, os EUA destacam-se com 14 publicações dentre os 30 países mencionados. Em relação ao tipo de publicação, a grande maioria consiste de artigos científicos $(65,6 \%)$. Já quanto à área de estudos, os resultados mostram grande variedade. Das 16 áreas mencionadas, em sua maioria as publicações são das áreas de Negócios, Administração e Contabilidade - $47,5 \%$ e Ciências Sociais $37,7 \%$.

No geral, os resultados relacionados à Pesquisa 1, pelos termos-filtro "creative entrepreneur" ou "creative entrepreneurship", mostram um aumento no número de publicações a partir de 2009, o qual se mostra constante, sendo $2012 \mathrm{o}$ ano de maior produção. Em relação à fonte de publicações, autor e instituição, nenhum mostra proeminência. Quanto ao país de origem, EUA mostra liderança, seguido por Reino Unido, Holanda,
Estônia e Canadá. Quanto ao tipo de documento, há predileção por artigos científicos. E quanto à área, Negócios, Administração e Contabilidade e Ciências Sociais respondem pela grande maioria. Importante lembrar que documentos podem estar catalogados em múltiplos países, autores, instituições, etc.

\subsection{PESQUISA 2}

A Pesquisa 2a, busca simples pelos termos-filtro "creative industries" e "entrepreneur", usando a variável AND, mostrou 66 documentos publicados entre os anos 2005 e 2015. Já a Pesquisa 2b, mesma busca usando os termos-filtro "creative industries" e "entrepreneurship", com a mesma variável $A N D$, mostrou 74 documentos publicados no mesmo período. A combinação de ambas buscas usando a variável $O R$, Pesquisa 2, mostrou 111 resultados. Sendo a soma dos dois totais 140 documentos, chegamos a um total de 29 documentos duplicados.

$\mathrm{O}$ ano de maior atividade foi 2015 , quando foram publicados 29 documentos. Quanto às fontes, são indicadas 71 , sendo o periódico com maior número de documentos relacionados o Journal of Small Business and Enterprise Development, com 4 documentos. Apesar de serem indicados 159 autores, nenhum mostrou proeminência, variando entre 1 ou 2 documentos publicados. No que diz respeito a instituições, foram indicadas 122, sendo proeminente a Queensland University of Technology, com 4 documentos. O país com 
maior número de publicações indicadas foi o Reino Unido, com 27 documentos. No total foram indicados 34 países. Quanto ao tipo de documento, há prevalência de artigos científicos 69,4\%. Já em relação à área, mostram-se proeminentes Negócios, Administração e Contabilidade (55\%) e Ciências Sociais $(49,5 \%)$.

A Pesquisa 2, busca pelos termos-filtro "creative industries" AND "entrepreneur" ou "creative industries" AND "entrepreneurship", mostra uma produção constante no período 2005-2015, com um aumento de 380\% no volume de publicações no biênio 2014-2015, sendo 2015 o ano de maior produção. O periódico que mostrou maior número de documentos foi o Journal of Small Business and Enterprise Development, do Reino Unido, que publicou 4 documentos. Nenhum autor dos 159 indicados mostrou proeminência. Quanto à instituições, das 122 mencionadas destacouse a Queensland University of Technology, com 4 documentos. Dos 34 países indicados, o Reino Unido teve o maior número de publicações com 27 documentos. Quanto ao tipo de documento, há prevalência de artigos científicos $(69,4 \%)$. Já em relação à área, mostram-se proeminentes Negócios, Administração e Contabilidade (55\%) e Ciências Sociais (49,5\%). Lembramos que um mesmo documento pode estar associado a diversos países, instituições, autores, etc.

\subsection{PESQUISA 3}

Realizando busca simples pelos termosfiltro "creative sectors" e "entrepreneur", com a variável $A N D$ (Pesquisa 3a), a base de dados mostrou 6 resultados; com os termos-filtro "creative sectors" AND "entrepreneurship" (Pesquisa 3b), 4 resultados, para um total de 10 documentos publicados no período 2005-2015. A combinação das duas buscas, com a variável OR (Pesquisa 3), resultou em 8 documentos indexados, com um total de 2 documentos duplicados.

Estas publicações estão concentradas em 4 dos 10 anos em que os termos-filtro foram usados, sendo 2010 o ano de maior produção. Em relação a autores, foram indicados 18; fontes, 7; instituições, 10 envolvidas. Nenhuma mostrou proeminência. O Reino Unido destaca-se com 3 documentos; os outros 7 países indicados têm 1 menção cada. Quanto a tipo de documento, 7 são artigos e 1 paper de conferência. Em relação à área, Ciências Sociais (50\%) mostram liderança, seguida por Negócios, Administração e Contabilidade $(37,5 \%)$. A Figura 7 melhor ilustra tais resultados.

A Pesquisa 3, combinação das buscas pelos termos-filtro "creative sectors" $A N D$ "entrepreneur" e "creative sectors" AND "entrepreneurship", com a variável $O R$, resultou em 8 documentos indexados, com um total de 2 documentos duplicados. $\mathrm{O}$ ano de maior produção foi 2010. Dos 18 autores, 7 fontes e 10 instituições envolvidos, nenhum mostra proeminência. Dentre os 8 países citados, o Reino Unido destaca-se com 3 documentos. Quanto a tipo de documento, 7 são artigos e 1 paper de conferência. Em relação à área, Ciências Sociais $(50 \%)$ mostram liderança, seguida por Negócios, Administração e Contabilidade (37,5\%). Lembramos que um mesmo documento pode estar associado a diversos países, instituições, autores, etc.

\subsection{PESQUISA 4}

A Pesquisa 4a, busca pelos termos-filtro "creative" AND "entrepreneur" gerou 688 resultados; já a Pesquisa 4b, busca por "creative" AND "entrepreneurship", resultou em 777 documentos, para um total de 1465 publicações. A combinação das buscas usando a variável $O R$, Pesquisa 4, gerou 1102 resultados entre os anos 1970 e 2015, com um total de 363 documentos sobrepostos em relação aos resultados individuais. Observamos um pico no desenvolvimento do tema a partir de 2000, sendo que entre 1970 e 1999 estão catalogados apenas 72 documentos, ou $6,5 \%$ num período de 30 anos. No período de 15 anos entre 2000 e 2015, no entanto, $93,5 \%$ dos documentos indicados foram publicados.

Quanto à fonte, dentre as 119 mencionadas, destaca-se o Journal of Business Venturing, com 20 documentos indexados. Do total de 158 autores, destaca-se Nijkamp, P. com 10 documentos publicados. Quanto à instituição, das 160 apontadas destaca-se Vrije Universiteit Amsterdam com 12 publicações. Dos 75 países envolvidos nas pesquisas, EUA tem lugar de destaque, com 344 documentos. Quanto ao tipo de documento, artigos 
científicos contam 699 dos 1102 resultados obtidos. No que diz respeito à área de estudo, Negócios, Administração e Contabilidade responde por $42,5 \%$ dos resultados, seguido por Ciências Sociais com 37,6\%. Os termosfiltro mostram a maior variedade de áreas envolvidas, sendo 23 áreas definidas, 1 indefinida, e 1 identificada como multidisciplinar.

No total, a Pesquisa 4, busca pelos termosfiltro "creative" AND "entrepreneur" ou "creative" AND "entrepreneurship", usando a variável $O R$, mostrou 1102 documentos, produzidos no período 1970-2015. A análise dos resultados mostra que $93,5 \%$ dos documentos foram produzidos no período de 15 anos a partir de 2000, sendo 2015 o ano de maior produção. Das 119 fontes mencionadas, destaca-se o Journal of Business Venturing. Dos 158 autores indexados, destaca-se Nijkamp, P. com 10 publicações. Quanto à instituição, Vrije Universiteit Amsterdam distingue-se com 12 documentos associados à ela. Do total de documentos indexados, 344 estão associados aos EUA, o dobro do segundo país mencionado. Quanto à área de estudo, Negócios, Administração e Contabilidade responde por $42,5 \%$ dos resultados, seguido por Ciências Sociais com 37,6\%. Lembramos que um mesmo documento pode estar associado a diversos países, instituições, autores, etc.

\subsection{PESQUISA 5}

Analisando os resultados das Pesquisas 14 e concentrando atenção nos números de documentos indexados resultantes de cada busca, consideramos a hipótese de haver sobreposição de resultados entre todas buscas, visto que o mesmo ocorreu nas 4 combinações realizadas. O Quadro 2 resume os números resultantes, considerando como campos: resultados das pesquisas "a" e "b", a soma dos resultados "a"+"b" (X), a combinação dos resultados "a" OR "b" (Y), e os resultados sobrepostos $(\mathrm{X}-\mathrm{Y})$, excluídos pela própria plataforma como resultado da combinação das buscas.

Quadro 2 - Resultados das Pesquisas 1-4 em termos de documentos indexados.

\begin{tabular}{|l|c|c|l|l|l|}
\hline & $\begin{array}{l}\text { Resultado } \\
\text { s "a" }\end{array}$ & $\begin{array}{l}\text { Resultado } \\
\text { s "b" }\end{array}$ & $\begin{array}{l}\text { Soma } \\
\text { resultados } \\
\text { "a"+"b" (X) }\end{array}$ & $\begin{array}{l}\text { Resultados } \\
\text { combinados } \\
\text { "a" or "b" (Y) }\end{array}$ & $\begin{array}{l}\text { Resultados } \\
\text { sobrepostos } \\
\text { (X-Y) }\end{array}$ \\
\hline Pesquisa 1 & 38 & 24 & 62 & 61 & 1 \\
\hline Pesquisa 2 & 66 & 74 & 140 & 111 & 29 \\
\hline Pesquisa 3 & 6 & 4 & 10 & 8 & 2 \\
\hline Pesquisa 4 & 688 & 777 & 1465 & 1102 & 363 \\
\hline
\end{tabular}

Fonte: elaborado pelos autores.

Para validar a hipótese de sobreposição de resultados, realizamos uma nova pesquisa. Esta consistiu da combinação das buscas salvas referentes às Pesquisas $1-4$, usando a variável $O R$ (Pesquisa 5), que confirmou a suposição de que haveria sobreposição de resultados, sendo que os resultados das Pesquisas 4 e 5 foram iguais. Ou seja, todos os documentos indicados na Pesquisa 4, que combinou as buscas por "creative" AND "entrepreneur" e "creative" AND "entrepreneurship", usando a variável $O R$, estão também indicados nas Pesquisas 1-3, cujos termos-filtro estão diretamente associados à Indústria Criativa.

\subsection{PESQUISA 6}

Os resultados encontrados na Pesquisa 5, associados a outros dados relacionados às buscas, a saber fonte e área, levaram-nos a conclusão de que os documentos de interesse ao estudo, a saber empreendedorismo criativo relacionado à Indústria Criativa, limitam-se aos resultados mostrados pelas Pesquisas 1-3. Estas foram consolidadas em nova pesquisa 
(Pesquisa 6), a qual é a de real importância para o estudo e analisaremos com mais detalhe. Para consolidar os dados destas buscas (Pesquisas 1-3), realizamos nova combinação com a variável $O R$ a partir das buscas salvas. Acreditamos que estes resultados mostram com maior fidelidade os dados relativos ao tema estudado.

Percebemos uma produção baixa no período 1989-2004, com uma média de 0,5 publicações ao ano. Entre 2005 e 2008, essa média sobe para 6,75 publicações. Já entre 2009 e 2013, esse número duplica, chegando a uma média de 14,6 publicações ao ano. Mais notável são os anos 2014, com 20 publicações, e 2015, com 36 documentos publicados. Tais números refletem o crescimento da produção científica sobre a Indústria Criativa, como apontado por Pinheiro; Barth (2014). O Gráfico 1 mostra o gráfico gerado pela plataforma SCOPUS.

Gráfico 1 - Número de publicações por ano, gráfico gerado pela plataforma SCOPUS.

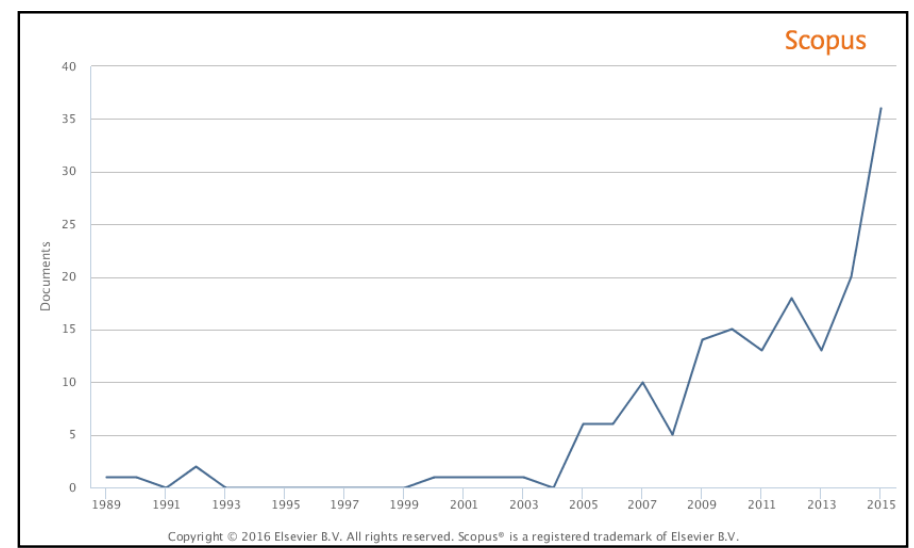

Fonte: SCOPUS, 2016, online.

De um total de 98 fontes citadas, destacase o Journal of Small Business and Enterprise Development com 4 documentos indexados. Em seguida, Education and Training, International Journal Of Arts Management, Management Decision e Small Business Economics mostram 3 documentos cada. As próximas 11 fontes listadas mostram 2 documentos cada, e 82 fontes publicaram 1 documento cada. O Gráfico 2 mostra a relação das principais fontes por quantia de documentos e ano de publicação.

Gráfico 2 - Principais fontes por quantia de documentos e ano de publicação, gráfico gerado pela plataforma SCOPUS.

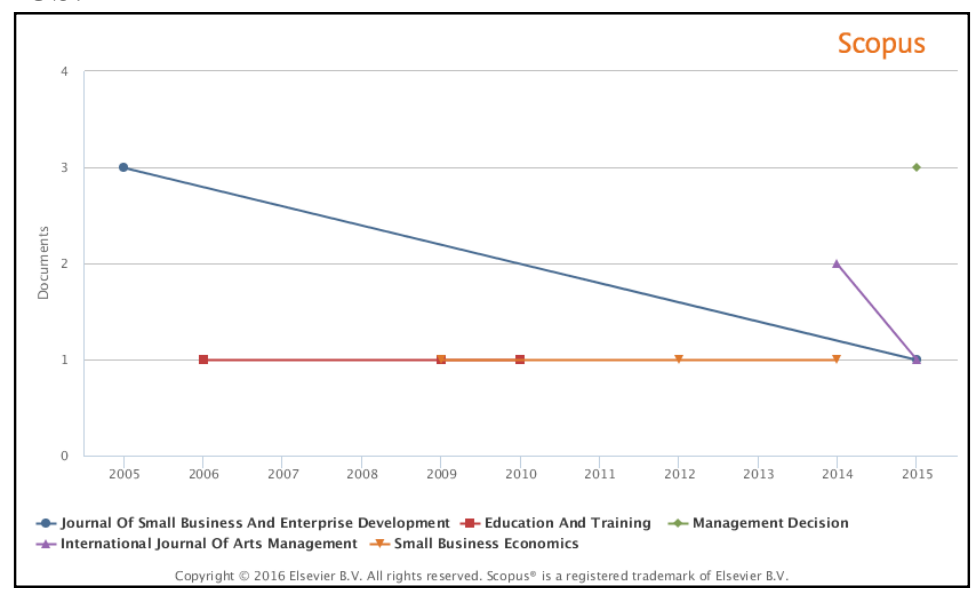

Fonte: SCOPUS, 2016, online. 
Quanto aos autores, nenhum destaca-se no quesito volume de produção. Dos 156 citados, 11 assinam 3 documentos cada, 21 autores assinam 2 documentos cada, e 125 autores são responsáveis por 1 documento cada. Cabe lembrar que um documento pode ser assinado por múltiplos autores. O Gráfico 3 lista, em gráfico gerado pela plataforma SCOPUS, os principais autores, com 3 publicações cada.

Gráfico 3 - Autores com maior número de publicações, gráfico gerado pela plataforma SCOPUS.

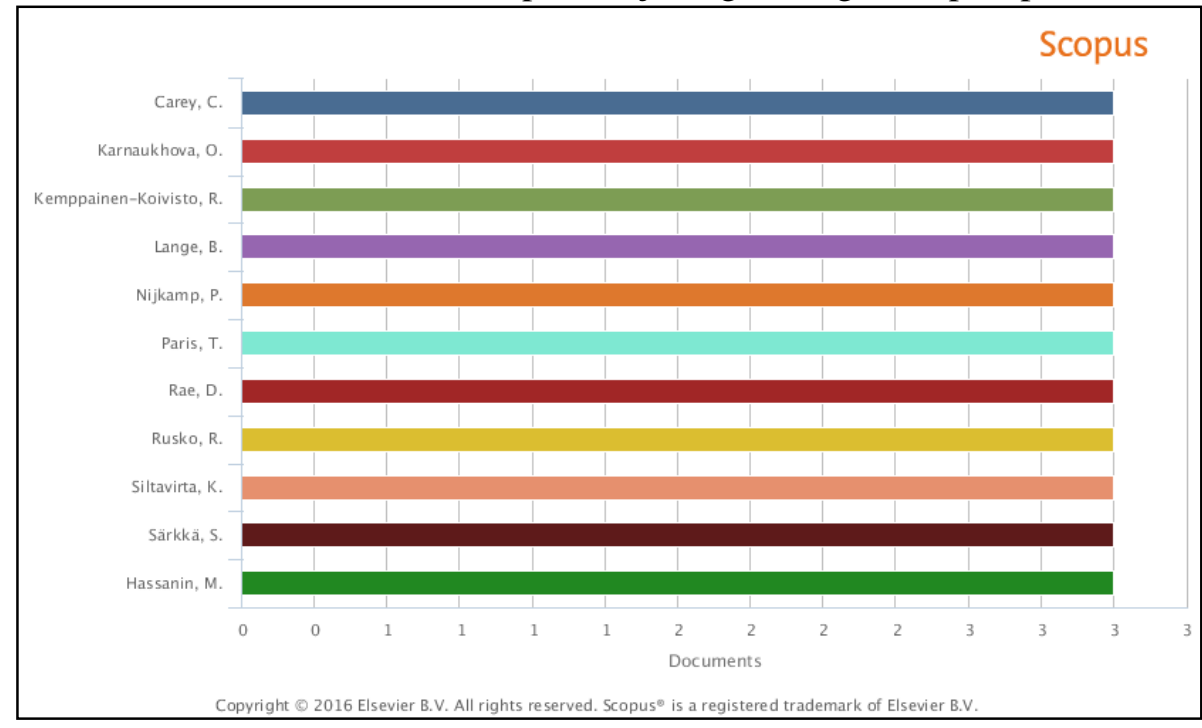

Fonte: SCOPUS, 2016, online.

No que diz respeito a Instituições de origem de publicações, foram apontadas 160 no total. Destacam-se Vrije Universiteit Amsterdam da Holanda e Queensland University of Technology - QUT da Austrália com 4 documentos cada. Seguindo, 5 instituições são responsáveis por 3 documentos cada, 19 instituições são responsáveis por 2 documentos cada, e 134 instituições estão ligadas a 1 documento cada. Vale lembrar que um mesmo documento pode estar associado a múltiplas instituições. O Grpafico 4 lista as principais instituições em número de publicações.

Gráfico 4 - Principais instituições por número de publicações, gráfico gerado pela plataforma SCOPUS.

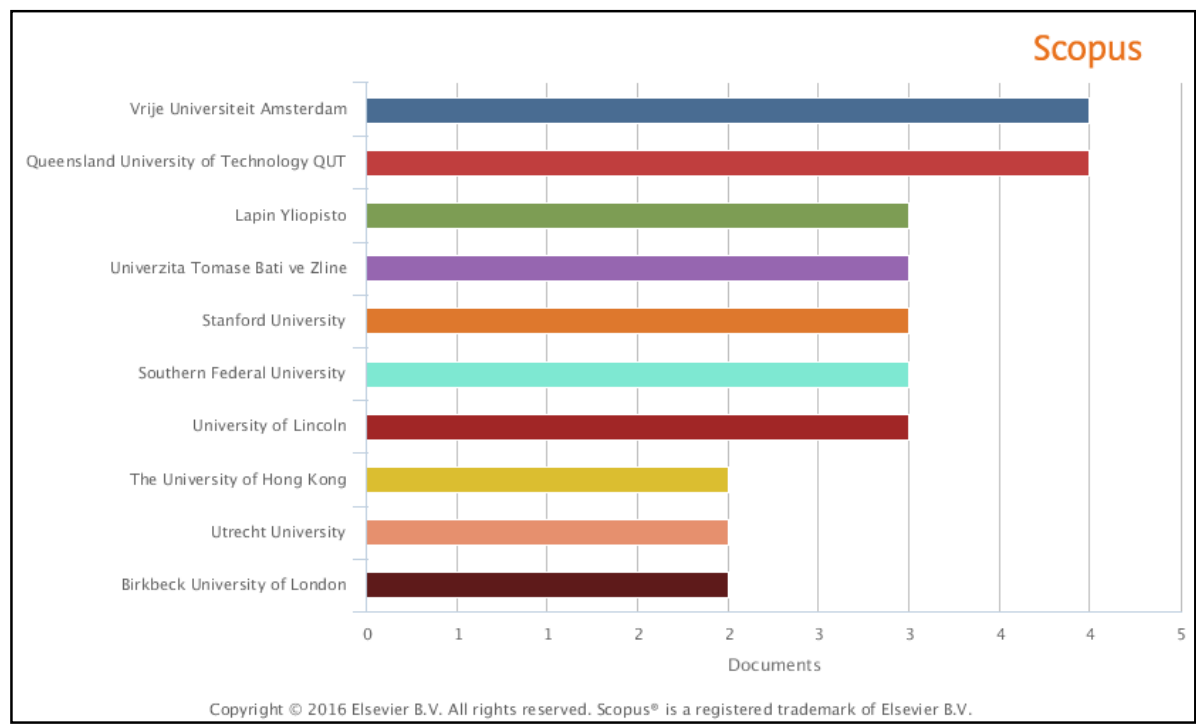

Fonte: SCOPUS, 2016, online. 
No que tange a país de origem dos documentos listados, a plataforma indica 42 países. Com 35 documentos, o Reino Unido lidera em produção, seguido pelos EUA com 22 documentos indexados. Austrália e Holanda seguem com 11 documentos cada. França e Espanha mostram 9 publicações cada,
Finlândia e Alemanha, 7 cada. Os restantes 33 países respondem por 77 documentos, uma média de 2,33 publicações por cada país. E 4 documentos têm país indefinido. Importante lembrar que um mesmo documento pode estar associado a diversos países. O Gráfico 5 ilustra os principais resultados indicados.

Gráfocp 5 - Países e número de publicações, gráfico gerado pela plataforma SCOPUS.

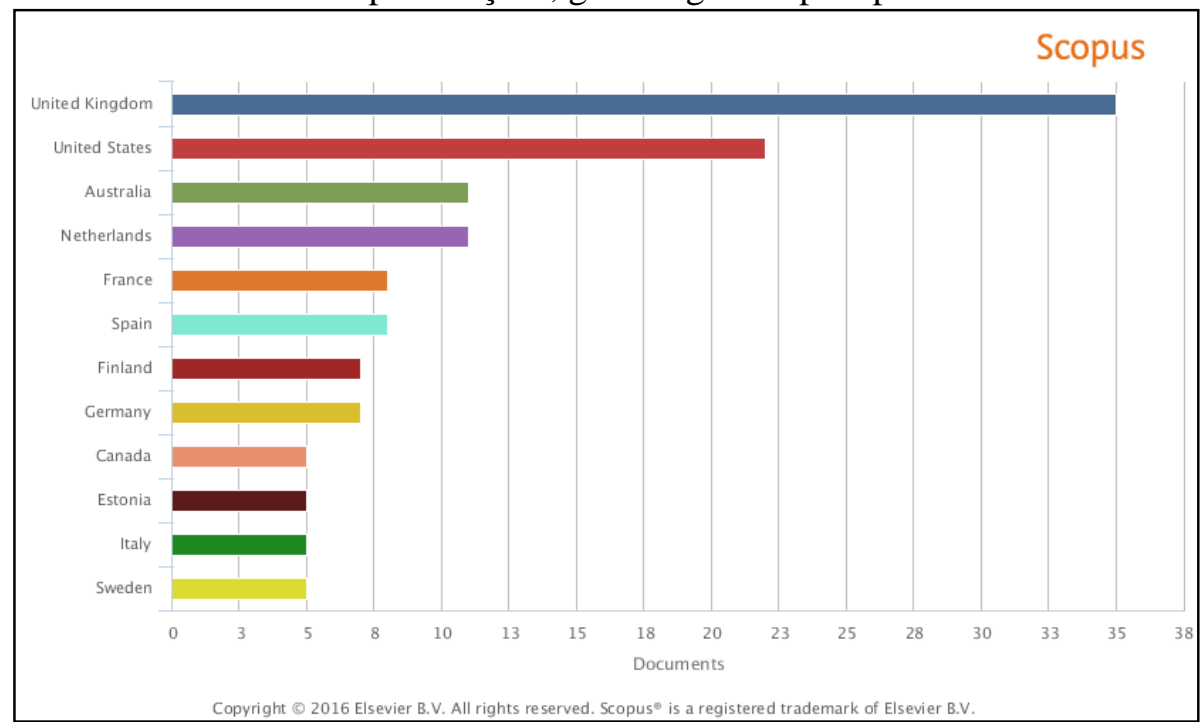

Fonte: SCOPUS, 2016, online.

Quanto aos tipos de documentos produzidos em relação ao tema estudado, percebemos uma predileção por artigos científicos, os quais respondem por 109 , ou $66,5 \%$ dos documentos indexados. Capítulos de livro somam 27 documentos, ou 16,5\%.
Foram indexados 14 papers de conferências $(8,5 \%), 10$ resenhas $(6,1 \%), 3$ livros $(1,8 \%)$ e 1 artigo no prelo $(0,6 \%)$. O Gráfico 6 ilustra esses números, em gráfico gerado pela plataforma SCOPUS.

Gráfico 6 - Tipo de documento produzido por porcentagem, gráfico gerado pela plataforma SCOPUS.

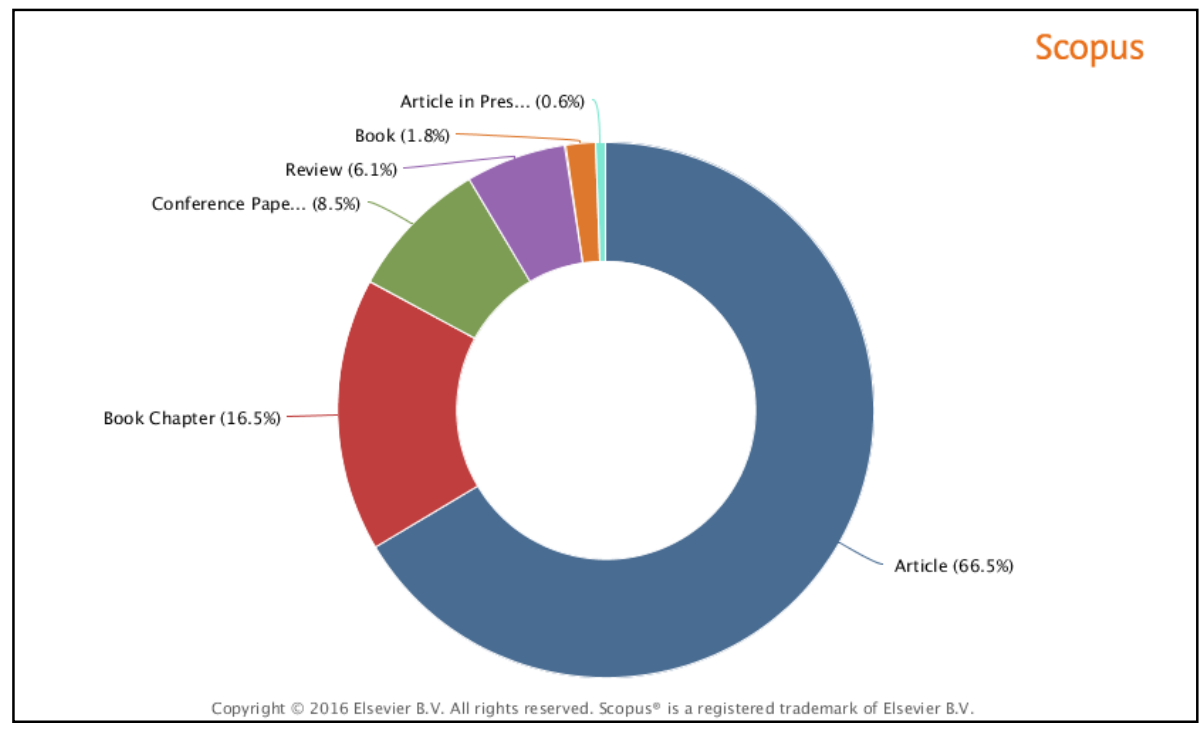

Fonte: SCOPUS, 2016, online. 
No que diz respeito a áreas de estudo relacionadas a Empreendedorismo Criativo relacionado à Indústria Criativa, 19 áreas são citadas. Mostra proeminência a área de Negócios, Administração e Contabilidade, com 84 documentos relacionados, um total de $51,2 \%$ dos resultados. Em seguida, 74 documentos foram indexados relacionados a Ciências Sociais no período estudado, respondendo por $45,1 \%$ dos documentos. Dos documentos restantes, 124 publicações estão associadas a 17 áreas de conhecimento, o que retrata a transição do tema entre diversas áreas do conhecimento. O Gráfico 7 mostra as principais áreas de conhecimento citadas, por porcentagem. Importante lembrar que um mesmo documento pode estar associado a diversas áreas de conhecimento.

Gráfico 7 - Áreas de conhecimento associadas aos documentos indexados, por porcentagem, gráfico gerado pela plataforma SCOPUS.

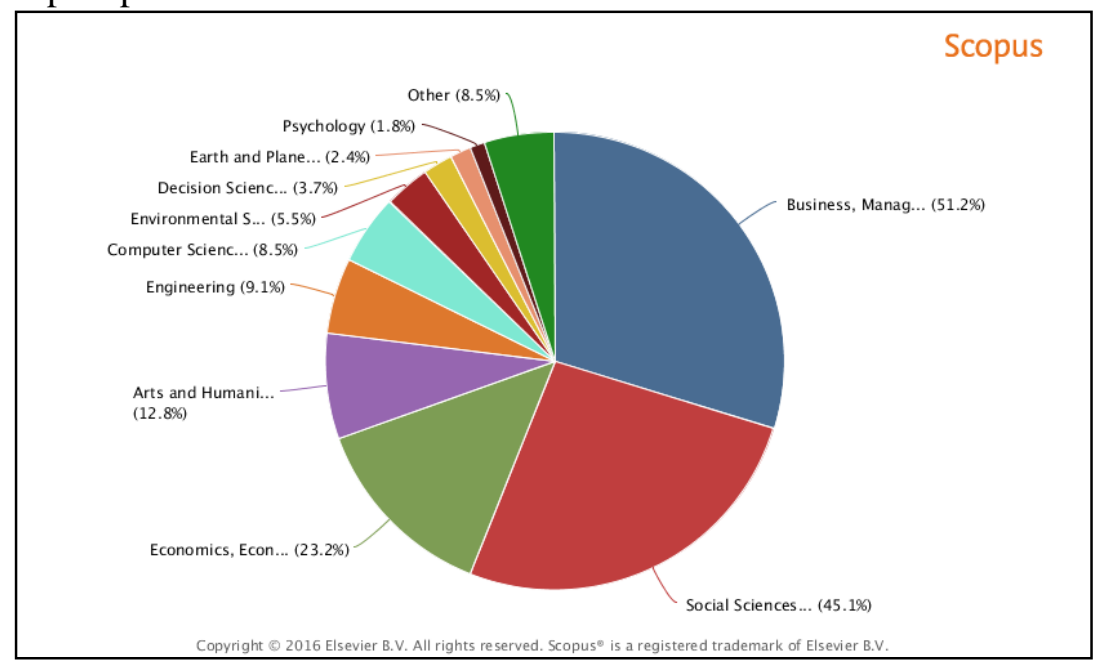

Fonte: SCOPUS, 2016, online.

Constatamos que a produção de documentos relacionados ao tema Empreendedorismo Criativo, associado à Indústria Criativa, mostra um desenvolvimento concentrado no período entre 2009 e 2015, sendo este último notável por um total de 36 documentos publicados. De 98 fontes citadas, destaca-se o Journal of Small Business and Enterprise Development com 4 documentos indexados. Quanto aos autores, nenhum dos 156 citados destaca-se no quesito quantia de publicações. No que diz respeito a Instituições de origem de publicações, foram apontadas 160 no total. Destacam-se Vrije Universiteit Amsterdam da Holanda e Queensland University of Technology - QUT da Austrália com 4 documentos cada.

No que tange a país de origem dos documentos listados, a plataforma indica 42 países, sendo o Reino Unido líder em produção com 35 documentos indexados. Quanto aos tipos de documentos produzidos, percebemos uma predileção por artigos científicos, os quais respondem por 109 , ou $66,5 \%$ dos documentos indexados. No que diz respeito a áreas de estudo relacionadas a Empreendedorismo
Criativo relacionado à Indústria Criativa, 19 áreas são citadas. Mostram proeminência a área de Negócios, Administração e Contabilidade, com 84 documentos relacionados, um total de $51,2 \%$ dos resultados; e Ciências Sociais, associada a 74 documentos, um total de $45,1 \%$ das publicações indexadas. Importante lembrar que um mesmo documento pode estar associado a diversos autores, instituições, países e áreas de conhecimento.

\section{CONSIDERAÇÕES FINAIS}

A partir do mapeamento sistemático da produção científica acerca do tema empreendedorismo criativo indexado na base de dados SCOPUS, procuramos realizar o retrato do movimento de publicações na área, validar a necessidade de pesquisas aprofundadas acerca do mesmo, e identificar a melhor terminologia para referência ao tema. O escopo foram os termos-filtro associados ao tema, a saber "empreendedor criativo"; "empreendedor" e "indústria criativa"; "empreendedor" e "setores criativos" e 
"empreendedor" e "criativo" usando a variável $A N D$. As buscas foram também realizadas substituindo o termo "empreendedor" pelo o termo "empreendedorismo". Realizamos também uma série de combinações dos resultados, as quais geraram os dados analisados - a saber, a combinação dos termosfiltro "empreendedor criativo", "empreendedor" e "indústria criativa" e "empreendedor" e "setores criativos".

A análise dos resultados aponta para uma maior produção relacionada ao assunto a partir do ano 2009, a fonte mais citada o Journal of Small Business and Enterprise Development. Em relação a autores, nenhum destaca-se com maior produção. No que diz respeito a Instituições de origem, destacam-se Vrije Universiteit Amsterdam da Holanda e Queensland University of Technology - QUT da Austrália com 4 documentos cada. No que tange a país o Reino Unido lidera em produção com 35 documentos indexados. Artigos científicos respondem por $66,5 \%$ dos documentos indexados. No que diz respeito a áreas de estudo relacionadas ao tema, mostram proeminência a área de Negócios, Administração e Contabilidade com um total de $51,2 \%$ dos resultados, e Ciências Sociais com um total de $45,1 \%$ das publicações indexadas. Importante lembrar que um mesmo documento pode estar associado a diversos autores, instituições, países e áreas de conhecimento.

De acordo com os resultados encontrados, a melhor nomenclatura para referência ao tema é Empreendedorismo na Indústria Criativa, por estarem disponíveis mais resultados associados a este segmento do campo científico Indústria Criativa. A proeminência das áreas Negócios, Administração e Contabilidade e Ciências Sociais confirma o lugar de proeminência dos campos Administração e Comunicação nos estudos relacionados ao tema. Também, validamos a relevância de futuros estudos, tendo em vista a escassez e o tangível crescimento da produção de conhecimento associado ao tema.

Recebido em: 15/03/2017

Aceito em definitivo em: 29/04/2017

\title{
CREATIVE ENTREPRENEURSHIP: SYSTEMATIC MAPPING OF LITERATURE IN SCOPUS PLATFORM
}

\begin{abstract}
We aim to carry out a systematic mapping of scientific production in the field of creative entrepreneurship associated with Creative Industry to establish the best nomenclature for studies related to the theme. Also, the portrayal of publications in the area and validation of the need for in-depth research on the subject. We performed a quantitative survey of a basic nature, which seeks bibliographic exploration of the subject following procedures pointed out by bibliometrics. We focus on documents available in the SCOPUS database, produced up to 2015. Result analysis indicates a higher production from the year 2009, being the year of greatest production 2015, the most cited source the Journal of Small Business and Enterprise Development. No author stands out with greater production. As for Institutions, we highlight Vrije Universiteit Amsterdam of the Netherlands and Queensland University of Technology - QUT of Australia with 4 documents each. The UK leads in production with 35 indexed documents, and scientific articles account for $66.5 \%$ of these. As far as areas of study are concerned, the Business, Administration and Accounting area stands out with $51.2 \%$ of the results, and Social Sciences with $45.1 \%$ of indexed publications. It is important to remember that the same document may be associated with several authors, institutions, countries and areas of knowledge. Results show Entrepreneurship in the Creative Industry as the best nomenclature for reference to the theme, as more results are available associated with this segment of the scientific field Creative Industry.
\end{abstract}

Keywords: Creative Entrepreneurship. Bibliometrics. SCOPUS. 


\section{REFERÊNCIAS}

BENDASSOLLI, P. F.; WOOD JR., T.; KIRSCHBAUM, C.; CUNHA, M. P. e. Indústrias criativas: definição, limites e possibilidades. ERA, v. 49, n.1, p. 10-18, jan./mar. 2009.

\section{BIRLEY, S.; MUZYKA,D. F. Dominando os desafios do empreendedor. São Paulo: MakronBooks, 2001.}

BRITISH COUNCIL. British Council Poland. Definition of a creative entrepreneur.

Disponível em

$<$ https://www.britishcouncil.pl/en/programme s/arts/yce-competition/definition-creativeentrepreneur $>$. Acesso em: 06 jan. 2016. CUNNINGHAM, S.D.. Aligning communication, cultural and media studies research and scholarship with industry and policy: Australian instances. Media International Australia incorporating Culture AND Policy, Brisbane, 2010, p.1319.

DCMS. Department for culture, media AND sports. Creative Britain: new talents for the new economy. 2008.

DEHEINZELIN, Lala. Economia Criativa e métodos para dar uma mão ao futuro. Redige, v. 2 n.02, ago. 2011.

DORNELAS, J.; TIMMONS, J. A.; SPINELLI, S.. Criação de novos negócios. Empreendedorismo para o século 21. São Paulo: Elsevier, 2010.

GUEDES, V. S.; BORSCHIVER, S.

Bibliometria: uma ferramenta estatística para a gestão da informação e do conhecimento, em sistemas de informação, de comunicação e de avaliação científica e tecnológica.

Salvador: VI CINFORM. 2005. Anais.

HANSON, D.. Indústrias criativas. Revista Eletrônica Sistemas \& Gestão, v. 7, n. 2, p. 222-238,2012.

HOWKINS, J. Economia criativa: como ganhar dinheiro com ideias criativas. São Paulo: M. Books, 2012.
NEWBIGIN, J. A economia criativa: um guia introdutório. Britsh Council, 2010.

PINHEIRO, C. M. P.; BARTH, M.; SCHMIDT, S.; SCHREIBER, D..

Mapeamento de conhecimento na plataforma Scopus: um estudo sobre a indústria criativa. RDBCI: Revista Digital de Biblioteconomia e Ciência da Informação, Campinas, SP, p. 329-342, maio 2015. ISSN 1678-765X.

Disponível em:

<http://periodicos.sbu.unicamp.br/ojs/index.p $\mathrm{hp} / \mathrm{rdbci} /$ article/view/8635336>. Acesso em: 09 ago. 2016.

doi:http://dx.doi.org/10.20396/rdbci.v13i2.86 35336.

\section{SEBRAE. Empreendedorismo no Brasil:} relatório executivo. Disponível em <http://www.sebrae.com.br/Sebrae/Portal\%20 Sebrae/\%20Estudos\%20e\%20Pesquisas/gem \%202014_relat\%C3B3rio\%20executivo.pdf>. Acesso em: 08 jan. 2016. 